\begin{tabular}{|c|c|}
\hline Citation/Reference & $\begin{array}{l}\text { Jeroen Dekervel, Daphne Hompes, Hannah van Malenstein, Dusan } \\
\text { Popovic, Xavier Sagaert, Bart De Moor, Eric Van Cutsem, André } \\
\text { D'Hoore, Chris Verslype, Jos van Pelt (2014), } \\
\text { "Hypoxia-Driven Gene Expression Is an Independent Prognostic Factor in } \\
\text { Stage II and III Colon Cancer Patients" } \\
\text { Clinical Cancer Research, 20(8), 2159-2168. }\end{array}$ \\
\hline Archived version & $\begin{array}{l}\text { Author manuscript: the content is identical to the content of the } \\
\text { published paper, but without the final typesetting by the publisher }\end{array}$ \\
\hline Published version & http://clincancerres.aacrjournals.org/content/20/8/2159.full \\
\hline Journal homepage & http://clincancerres.aacrjournals.org/ \\
\hline Author contact & $\begin{array}{l}\text { dusan.popovic@esat.kuleuven.be } \\
+32(0) 16328647\end{array}$ \\
\hline IR & https://lirias.kuleuven.be/handle/123456789/438566 \\
\hline
\end{tabular}




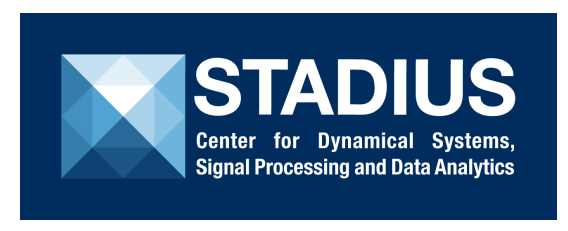

KU LaUVEN

(article begins on next page) 


\section{Hypoxia driven gene expression is an independent prognostic factor in stage II and III colon cancer patients}

Jeroen Dekervel ${ }^{1}$, Daphne Hompes ${ }^{2}$, Hannah van Malenstein ${ }^{1}$, Dusan Popovic ${ }^{3}$, Xavier Sagaert ${ }^{4}$, Bart De Moor ${ }^{3}$, Eric Van Cutsem ${ }^{5}$, André $\mathrm{D}^{\prime}$ Hoore $^{2}$, Chris Verslype ${ }^{1,5}$ and Jos van Pelt ${ }^{1}$

1) Laboratory of Hepatology, University Hospitals Leuven \& Department of Clinical and Experimental Medicine, KU Leuven, Belgium

2) Department of Abdominal Surgical Oncology, University Hospitals Leuven, Belgium

3) Department of Electrical Engineering (ESAT), STADIUS - iMinds Future Health Department, KU Leuven, Belgium

4) Department of Imaging \& Pathology, University Hospitals Leuven, Belgium

5) Department of Clinical Digestive Oncology, University Hospitals Leuven, Belgium

Running title: Hypoxia driven prognostic gene score in colon cancer

Keywords: colon cancer, hypoxia, biological markers, gene expression, formalin-fixed paraffin

embedded tissue

Grant support: JD is supported by the Flemish League against Cancer (VLK). XS is a Senior

Clinical Investigator of the Fund for Scientific Research - Flanders (FWO-Vlaanderen).

\section{Corresponding author:}

Jos van Pelt

Herestraat 49 , bus 703

3000 Leuven

Tel.: 0032-16-330694

Fax: 0032-16-330701

E-mail: Jos.vanPelt@med.kuleuven.be

Disclosures: The authors report no conflict of interest.

Transcript Profiling: GSE31079

Word count: 3828 (excl ref) - Number of figures: 3 - Number of tables: 4 


\section{Statement of translational relevance}

Hypoxia is a well known microenvironmental factor determining tumor behavior. Despite this knowledge, its influence is never taken into account in clinical practice. We looked at gene expression changes in colon cancer cells exposed to chronic hypoxia. The hypoxia induced expression pattern correlated with the clinical outcome of more than 200 colon cancer patients in published microarray data sets confirming the detrimental role of intratumoral hypoxia on prognosis. We further describe the development of a 6 gene Colon Cancer Hypoxia Score (CCHS) which was found prognostic in two additional patient cohorts. Its value was independent of other important variables such as disease stage, differentiation grade and vascular invasion. Moreover, the CCHS performed excellent in both fresh frozen as well as in paraffin embedded material. 


\section{Abstract}

Purpose - Hypoxia is considered a major microenvironmental factor influencing cancer behavior. Our aim was to develop a hypoxia-based gene score that could identify high and low risk within stage II and III colon cancer patients.

Experimental design - Differential gene expression of CaCo-2 colon cancer cells cultured in chronic hypoxia versus normoxia was tested for correlation with prognostic variables in published microarray data sets. These data sets were further used to downsize and optimize a gene score, which was subsequently determined in paraffin embedded material of 126 patients with colon cancer treated in our center.

Results - In the CaCo-2 cells, 923 genes with a 2-fold change and Limma corrected $p \leq 0.0001$ were found differentially expressed in hypoxia versus normoxia. We identified 21 genes with prognostic value and overlapping in three different training sets and $(n=224)$. With a fourth published data set $(n=177)$, the six gene Colon Cancer Hypoxia Score (CCHS) was developed. Patients with low CCHS showed a significant better disease free survival at three years (77.3\%) compared to high CCHS patients (46.4\%) (Log rank, $p=0.006)$. This was independently confirmed in an external patient cohort of 90 stage II patients ( $86.9 \%$ vs $52.2 \%, p=0.001)$.

Conclusions - Hypoxia driven gene expression is associated with high recurrence rates in stage II and III colon cancer. A 6-gene score was found to be of independent prognostic value in these patients. Our findings require further validation and incorporation in the current knowledgee on molecular classification of colon cancer. 


\section{Manuscript}

\section{Introduction}

In Western countries, colorectal cancer (CRC) is the third most common cancer in both men and women and the second leading cause of cancer-related death, accounting for approximately 500.000 deaths annually (1). Tumor stage (American Joint Committee on Cancer - AJCC) at presentation is the main factor for therapeutic decisions and prognostic estimates. Patients with stage II disease generally undergo surgery only, whereas in stage III, adjuvant chemotherapy after resection of the affected bowel segment and attached lymph nodes is the preferred treatment option (2). However, data from historical trials shows that $60 \%$ of stage III patients do not recur following surgery only whereas $20 \%$ of stage II patients do have recurrent disease after resection $(3,4)$. These findings have led to an extensive search for prognostic markers that could classify CRC patients more accurately, reducing over- or undertreatment. The finding that stage II patients with a high degree of tumor microsatellite instability (MSI-H) are at very low risk of recurrence helps guiding treatment (5). Driven by the success of this approach in breast cancer (6), extensive research has led to the development of dozens of prognostic gene signatures for colon cancer (7). Although used by some oncologists, gene signatures are currently not approved by the FDA nor adopted by any CRC treatment guideline (8).

In this study, the aim was to develop a robust prognostic gene score to improve the subclassification of stage II and III colon cancer patients using a mechanism based approach previously described for hepatocellular carcinoma (9). It is now recognized that 
microenvironmental factors such as hypoxia play a role in tumor behavior. Exposed to low oxygen supplies cancer cells become more aggressive, invasive and resistant to therapy (10). In vitro, we identified the differentially expressed genes under chronic hypoxia versus normoxia. Using bioinformatics on 3 published sets of expression data with corresponding clinical information we could identify 21 genes, related to both hypoxia and prognosis. Further optimization of the model led to a Colon Cancer Hypoxia Score (CCHS) of 6 genes which we evaluated in formalin-fixed, paraffin-embedded (FFPE) tissue of our own patient cohort as well as in an external data set. 


\section{Methods}

\section{Cell culture and RNA isolation}

Method details are described in the supplementary files. Briefly, as in vitro model we used the human adenocarcinoma cell line CaCo-2 (HTB-37; ATCC, Rockville, MD, USA). Cells were grown in a humidified incubator (Sanyo MCO-18M O2/CO2 incubator, Osaka, Japan) $\left(5 \% \mathrm{CO}_{2}\right.$ at $37^{\circ} \mathrm{C}$ ) in MEM medium (InVitrogen, Merelbeke, Belgium) supplemented with $10 \%$ fetal calf serum, 2 $\mathrm{mM} \mathrm{L-glutamine,} 100 \mathrm{U} / \mathrm{ml}$ penicillin, $100 \mu \mathrm{g} / \mathrm{ml}$ streptomycin and $1 \mathrm{mM}$ sodium pyruvate.

For the determination of chronic hypoxia conditions by RT-PCR, cells were seeded in $25 \mathrm{~cm}^{2}$ culture flasks $\left(10^{6}\right.$ cells/flask) that were placed in either $2 \% \mathrm{O}_{2}$ or $20 \% \mathrm{O}_{2}$ after $24 \mathrm{~h}$ attachment. All culture conditions were performed in triplicate and cells were collected for RNA isolation at $0,10,24,48$ and 72 hours.

For microarray analysis, cells were seeded at $3 \times 10^{6}$ in $75 \mathrm{~cm}^{2}$ tissue culture flasks $(\mathrm{n}=4)$ at $20 \%$ $\mathrm{O}_{2}$ and were grown until $70 \%$ confluence. After reaching near-confluence, 2 flasks were placed in a humidified incubator with hypoxic conditions $\left(2 \% \mathrm{O}_{2}, 5 \% \mathrm{CO}_{2}\right.$ at $\left.37^{\circ} \mathrm{C}\right)$ for $72 \mathrm{~h}$, while two other flasks remained in normoxic conditions $\left(20 \% \mathrm{O}_{2}\right)$.

Cells were harvested after trypsin treatment and mixed with Trizol (InVitrogen). RNA was isolated with the RNeasy Kit (Qiagen, Chatsworth, CA) according to the manufacturer's instructions.

\section{$R T-P C R$}

RNA was reverse transcribed into cDNA using SuperScript II reverse transcriptase and random hexamer primers (InVitrogen). The PCR reaction was carried out using TaqMan Universal PCR Master Mixture and Assays-on-Demand ${ }^{\mathrm{TM}}$ Gene Expression products (Applied Biosystems, 
Foster City, California). The primers used are listed in supplementary table S1. Beta-2 microglobulin was used as housekeeping gene. Real-time PCR amplification and data analysis were performed using the A7500 Fast Real-Time PCR System (Applied Biosystems, Foster City, California). The $\Delta \Delta$ Ct-method was used to determine relative gene expression levels.

\section{Microarray}

Samples were hybridized on dual color Agilent's Human Whole Genome Oligo Microarray (Cat\# G4112F, Agilent, Diegem, Belgium) that contained 44k 60-mer oligonucleotide probes representing around 41000 well-characterized human transcripts. Sample processing, quality control and microarray data analysis is described in detail in the supplementary methods. To identify the highly significant differentially expressed genes under chronic hypoxic conditions, probes with a 2-fold change and a corrected p-value below 0.0001 after multiple testing correction were selected (11). Results were confirmed by performing RT-PCR on selected genes.

\section{Correlation of the hypoxia gene expression pattern with prognosis in external data sets}

Biomarker development and evaluation was done following the REMARK guidelines for tumor marker studies (12). In order to determine the clinical relevance of the hypoxia gene expression pattern we compared our findings with published microarray data sets containing corresponding clinical information.

We considered four data sets of colon carcinoma patients, published in Gene Expression Omnibus (GEO) (Table 1), all based on the GeneChip Human Genome U133 Plus 2.0 array from Affymetrix. In Jorissen et al., 63 microsatellite stable (MSS) and 11 unstable (MSI) colorectal cancer samples from the Royal Melbourne Hospital were investigated (13). In Aronow et al., 
recurrence status was available for 100 colon cancer patients after exclusion of mucosa samples (14). 232 patients with colon cancer and known clinical outcome were included in the study by Smith et al. (15). This set was divided into 55 samples from Vanderbilt Medical Center (referred to as VMC) and 177 samples from the Moffitt Cancer Center (MCC).

All data sets were independent of one another, except for the data set of Aronow et al., which shows partial overlap with MCC samples (own observations). For this reason, we used the data sets of Jorissen and Aronow and the VMC subset of Smith to determine the prognostic value of the hypoxia gene expression pattern with a global test by Goeman (16).

Subsequently, overlap between the hypoxia gene expression pattern and the three data sets was used to downsize the number of genes (prognostic signature, see figure 1).

The MCC subset of Smith was used to optimize this signature by backward regression analysis using SPSS package 19 (IBM, Armonk, New York). A probability of F with a p-value of 0.05 was set as the treshhold for entry and removal. This way, we selected those genes that contributed the most to the model and enriched them with a coefficient which describes the relative contribution of the gene. The obtained score was named the "Colon Cancer Hypoxia Score"(CCHS).

\section{Prospective evaluation of the Colon Cancer Hypoxia score}

The Leuven cohort - 162 patients with stage II or III colon cancer treated in our center between 2004 and 2006 were selected to test the performance of the CCHS. Patients with missing clinical data, patients with rectal cancer and those who did not survive at least one month after surgery were excluded. For this study, we used two parallel slides of FFPE material per patient. The first slide was H\&E stained, and the tumor tissue marked by a pathologist. Tumor was then 
dissected from non-tumorous tissue on the second slide and subsequently deparaffinized. RNA was extracted using a modified RNeasy FFPE protocol (supplementary methods). Quantification, sizing and quality control was performed with the Bioanalyzer platform (Agilent). Only samples with at least $50 \%$ of RNA fragments longer than 200 bases were selected. Samples were analyzed for expression of selected genes by the nCounter technique (NanoString Technologies, Seattle, WA) which gives a direct read-out of transcripts without the use of enzymatic reactions (17). The used CodeSet is described in supplementary table S2.

The Amsterdam cohort - The AMC-AJCCII-90 data set consists of gene expression data on fresh frozen tumor tissue of 90 stage II patients treated in the Academic Medical Center in Amsterdam between 1997 and 2006. The Affymetrix Human Genome U133 Plus 2.0 Array was used as microarray platform (GSE33113) (18).

\section{Statistics}

All data are presented as median with range. A p-value $<0.05$ was considered significant. To determine an optimal cutoff value for our Colon Cancer Hypoxia Score, a receiver operating characteristic (ROC) curve was used. For the survival analysis, Kaplan-Meier survival curves and univariate and multivariate Cox proportional hazard ratio were used. All statistics were performed using SPSS package 19 (IBM). 


\section{Results}

\section{Dynamics in gene expression in CaCo-2}

To investigate the dynamics of hypoxia related gene expression in our in vitro model and to determine the optimal timing for microarray analysis we performed RT-PCR at different time points for a set of 8 representative genes known to be responsive to hypoxia. Gene expression was tested at $0 \mathrm{~h}, 10 \mathrm{~h}, 24 \mathrm{~h}, 48 \mathrm{~h}$ and $72 \mathrm{~h}$ in hypoxia $\left(2 \% \mathrm{O}_{2}\right)$ versus normoxia. It should be noted that when CaCo-2 cells were kept beyond 72 hours their cultures tended to become super-confluent with partly detachment of the cells resulting in an uncontrolled fluctuation of the gene expression levels (data not shown). Most of the mRNA expression levels investigated showed a dynamic curve over time at $2 \% \mathrm{O}_{2}$ with exception of $B C L 2$ that did not change significantly at any of the time points investigated (supplementary figure S1). These observations support the assumption that the acute hypoxic state (up to $24 \mathrm{~h}$ ) has a different gene expression pattern compared to the more chronic state (72 hours). As such, we chose the latter condition for our microarray experiment.

\section{Microarray: primary data analysis and development of a Colon Cancer Hypoxia Score}

Using Agilent technology, in CaCo-2 cells cultured for 72 hours at either $20 \%$ oxygen or in hypoxic conditions at $2 \%$ oxygen a total of 37,707 spots showed a representative signal of which 3,389 with a ${ }^{2} \log$ fold change $>1$ or $<-1$ and a Limma corrected $p$-value $<0.05$. These microarray data are available at NCBI under number GSE31079.

For the development of our gene signature, we started with the top 923 differentially expressed genes (with a ${ }^{2} \log$ fold change $>1$ or $<-1$ and a Limma corrected $p$-value $<0.0001$ ): the hypoxia gene expression pattern. Of those 923 genes, 704 were up-regulated and 219 down- 
regulated in hypoxic conditions. The top altered genes and significant KEGG pathways involved are listed in supplementary table S3-S4.

Subsequently, the Goeman global test showed that the overall expression pattern of these hypoxia genes was significantly related to the prognostic factor considered for each of the three training data sets ( $\mathrm{p}$-value $<0.0001$ for Jorissen, $\mathrm{p}$-value $=0.00028$ for Aronow and $\mathrm{p}$-value $=$ 0.0107 for Smith VMC).

Next, when only keeping the significant genes with a z-score above 1, 530 genes remained for the data set of Jorissen, 360 genes for Aronow, and 338 genes for Smith VMC. Finally, genes for which the direction of altered expression did not correspond to the direction observed in vivo in at least 2 out of 3 data sets were removed. With this approach, we were able to downsize the number of genes to twenty-one, found to overlap between the three training data sets (figure 1). In this gene set of 21 genes, 17 genes were upregulated in hypoxic conditions and 4 were downregulated (table 2).

CaCo-2 cells contain a TP53 mutation resulting in undetectable p53 protein levels (19). As such, TP53 was not considered early in the development of our gene signature despite being clinically of potential prognostic importance in colon cancer (20). For these reasons, TP53 was added afterwards to the in vitro-derived 21 hypoxia cancer genes.

Using a backward linear regression analysis with the 21 genes and TP53 as independent variables and the AJCC disease stage of patients in a fourth data set (Smith MCC) as dependent variable, six genes showed the highest contribution to the model. These genes with their corresponding coefficient form the Colon Cancer Hypoxia Score (figure 1). The score consists of 
the expression value of BCCIP, GADD45B, INSIG2, BNIP3L, MPHOSPH6 and TP53. The latter three have an inverse effect on the score value. All genes are involved in processes related to cell cycle, apoptosis and DNA repair.

\section{Prospective evaluation of CCHS}

Of the 162 stage II/III patients treated in our center between 2004 and 2006, 129 were selected for nCounter analysis after exclusion of clinical abberant cases and quality control (figure 2). Gene expression level of the CCHS genes was successfully obtained in 126 samples $(97.7 \%)$. The known clinical and pathological features of these patients are summarized in table 3. Estimated median disease free survival times were 66.2 months (95\% Cl $60-71.5)$ and 46 months $(95 \% \mathrm{Cl}$ $37.5-54.5)$ for stage II and stage III patients, respectively.

Using an optimal cut-off (see supplementary figure S2), patients with a low CCHS showed to have significant better disease free survival (DFS) at three years compared to those with a high CCHS $(77.3 \%$ vs $46.4 \%$ respectively, $\mathrm{p}=0.006)$. These DFS rates remained unchanged at five years. Median disease free survival was 62,2 months (95\% Cl 56.6-67.7) and 42.7 months (95\% $\mathrm{Cl} 33.4$ - 52) for CCHS low and CCHS high patients respectively ( $p=0.006)$ (figure 3a). Patients with a favorable CCHS were more likely to be alive at three years (estimated overall survival $81.5 \%$ vs $66.6 \%, p=0.044)$ and at five years $(71.9 \%$ vs $59.1 \%, p=0.036)$.

When disease AJCC stage was taken into account, survival analysis could identify three groups with significant difference in survival (figure 3b). Patients with stage II disease and unfavorable CCHS had almost similar disease behavior as stage III patients with a good (low) Colon Cancer Hypoxia Score. Moreover, the CCHS could identify a subgroup of stage III patients with an 
estimated recurrence rate at three years of $75 \%$ and a median disease free survival of only 28.2 months $(95 \% \mathrm{Cl} 16-40.4)$.

The characteristics of the 90 patients of the Amsterdam cohort are listed in table 3. Estimated disease free survival time for the whole cohort was 95.5 months (95\% Cl $85.8-105.2)$. Similar to the Leuven patient cohort, the CCHS identified two subgroups of stage II patients with different DFS at three years $(86.9 \%$ vs $52.2 \%, p<0.001)$ and five years $(86.9 \%$ vs $52.2 \%, p<$ 0.001). Median disease free survival was 102.5 months $(95 \% \mathrm{Cl} 93.1-111.9)$ vs. 55.4 months $(95 \% \mathrm{Cl} 38.7-72)(p=0.001)$ (figure $3 c)$. Hazard ratio for recurrence in CCHS high versus CCHS low patients was $3.970(95 \% \mathrm{Cl} 1.6-9.8)(p=0.004)$.

Subsequently, a univariate Cox regression analysis was performed on the Leuven cohort analyzing all known clinical and pathological variables. Four variables with significant prognostic value were included in a multivariate analysis. The multivariate Cox regression model confirmed that the Colon Cancer Hypoxia Score is a predictor for recurrence independent of disease stage, venous invasion and the number of examined lymph nodes (table 4).

\section{Discussion}

Colon cancer is associated with high morbidity and mortality and prognostic subclassification of stage II and III patients remains an ongoing clinical challenge. We describe the development and testing of a mechanism based prognostic gene score. Hypoxia as microenvironmental factor is well known for its influence on cancer behavior. If hypoxia does not induce cell death, it increases tumor aggressiveness, invasiveness and metastatic potential mainly through activation of the hypoxia-inducible factor (HIF) pathway (10). Despite this knowledge, hypoxia is 
seldom taken into account in the clinical setting in part due to the lack of good endogenous hypoxia markers (21). HIF overexpression has been proven associated with prognosis, but HIF itself is not considered to be a hypoxia marker exclusively due to the fact that it can be activated in various settings including oncogene drive (22). Our method shows a correlation between the altered expression of hundreds of genes under hypoxic conditions in vitro, with that of tumors in published microarray data sets with clinical data available. This confirms the role of intratumoral hypoxia in disease behavior as was previously shown in HCC (9).

Colon cancer is subject to extensive global scientific research and many gene signatures and scores have been developed in the past mostly based on hierarchical clustering. Some of these signatures have made it to commercially available tests. Although a promising approach to capture the complexity of cancer biology, few signatures show good power in external patient cohorts (7). We tried to address these limitations by using a mechanism-driven approach and involving different data sets in the development of our signature. This resulted in a workable amount of genes derived from data of over 400 patient samples. Moreover, we hypothesized that the optimization process with a backward regression model has added power to the prognostic value of the genes.

p53 is a known important tumor suppressor in colon cancer and its pathway is modulated by hypoxia (23). This is further supported by our findings that, in vitro under hypoxic conditions, the p53 pathway is a highly significant altered KEGG pathway (supplementary table S4 and figure S3). For this reason and those stated above, TP53 was appended to the gene list in the knowledge that the backward regression analysis would eliminate this gene immediately in the 
absence of an added value to the model. The fact that it was withheld in the CCHS suggests that TP53 gene expression is of prognostic value for colon cancer patients.

Evaluation of the CCHS was done in formalin-fixed paraffin-embedded material. For mRNA level measurements, this type of material often presents a challenge as it is subjected to RNA degradation. After strict quality control (figure 2), the nCounter platform showed excellent performance and reliability for determining the expression levels of all 6 CCHS genes. Independent of other clinical and pathological parameters, the CCHS was found to predict relapse in stage II and III colon cancer. In stage II patients, it identified a high risk subgroup that might benefit from adjuvant therapy. Furthermore, stage III patients with unfavorable CCHS suffer from high recurrence rates.

Recently, progress has been made in the field of molecular classification of colon cancer based on gene expression clustering, epigenetic markers and therapy response. This approach led to the proposition of 3 to 6 CRC subtypes $(18,24,25)$. De Sousa et al identified two classes which seem to represent the known subgroups of MSI/CIMP and chromosomal-instable (CIN) tumors respectively (18). A third class, previously unidentified and related to serrated polyps, was associated with a poor prognosis. Tumors of this subgroup have stemness features, which is in line with others who have isolated a stem cell or epithelial-to-mesenchymal transition (EMT) associated subgroup of colon cancer patients with high recurrence rates (24-26). We see a striking overlap between the KEGG pathways involved in adapting to hypoxic conditions and those pathways attributed to the stem cell-like phenotype proposed by Marisa et al (25) (supplementary table S4). Further prospective validation in a larger patient cohort is needed to 
clarify whether a high CCHS is indicative for the stemness subtype. If so, the limited number of genes together with the performance in FFPE samples render our CCHS a potential clinical tool. This study has some limitations. Unfortunately, at the time of study onset, extensive clinical data were not available for some of the published data sets used for CCHS development. This forced us to use surrogate parameters such as microsatellite instability which could influence the power of the obtained score. During study design, after careful evaluation of the available information, considerable overlap between different data sets published in the Gene Expression Omnibus was noticed. For example: most samples of the data set provided by Aronow et al. (GSE5206) have also been included in both GSE14333 and GSE17536 (own observations). This requires great caution when designing studies with this widely used published data. In our case, we compared the individual patient data of the data sets and found that there was a partial overlap between the database by Aronow and Smith MCC. In our study design, the latter was only involved in optimization of the gene signature and this overlap should therefore not affect our conclusions.

When testing the performance of the CCHS we excluded rectal cancer. Despite the obvious similarities between colon and rectal cancer, we wanted to exclude the differences in treatment modalities as a confounder. As such, our results cannot be extrapolated to these patients.

Finally, our study was designed to evaluate the CCHS as a prognostic marker. Further research is needed to determine whether the score has predictive abilities, ie. potency to identify patients likely to benefit from adjuvant treatment. 
In conclusion, we discovered that the gene expression pattern of CaCo-2 cells cultured in hypoxia shows good correlation with clinical parameters of colon cancer patients in published microarray data sets. This confirms the importance of intratumoral hypoxia in disease behavior. From this point, a 6 gene Colon Cancer Hypoxia Score was developed which proved to be an independent prognostic biomarker for relapse in stage II and III colon cancer.

\section{Acknowledgements}

The authors thank P. Windmolders for her excellent technical assistance and prof. F. Nevens for his support. nCounter analysis was performed by VIB Nucleomics Core (Dr. R. van Eijsden and Dr. J. Allemeersch) (www.nucleomics.be). We thank Dr. A. Daemen (ESAT) for her contribution to the set-up of this study and the VIB SWITCH laboratory (prof. J. Schymkowitz and prof. F. Rousseau) for their cooperation and discussion of the results.

Research supported by GOA/10/09 MaNet, IWT: TBM Rectal Cancer, iMinds SBO, VLK Stichting E. van der Schueren: rectal cancer, Federal Government Cancer Plan 2012-2015 KPC-29-023 (prostate). The scientific responsibility is assumed by its authors. 


\section{References}

1. Ferlay J, Shin HR, Bray F, Forman D, Mathers C, Parkin DM. Estimates of worldwide burden of cancer in 2008: GLOBOCAN 2008. Int J Cancer 2010;127:2893-917.

2. Schmoll HJ, Van Cutsem E, Stein A, Valentini V, Glimelius B, Haustermans K, et al. ESMO Consensus Guidelines for management of patients with colon and rectal cancer. A personalized approach to clinical decision making. Ann Oncol 2012;23:2479-516.

3. Moertel CG, Fleming TR, Macdonald JS, Haller DG, Laurie JA, Tangen CM, et al. Fluorouracil plus levamisole as effective adjuvant therapy after resection of stage III colon carcinoma: a final report. Ann Intern Med 1995;122:321-6.

4. Quasar Collaborative G, Gray R, Barnwell J, McConkey C, Hills RK, Williams NS, et al. Adjuvant chemotherapy versus observation in patients with colorectal cancer: a randomised study. Lancet 2007;370:2020-9.

5. Tejpar S, Bertagnolli M, Bosman F, Lenz HJ, Garraway L, Waldman F, et al. Prognostic and predictive biomarkers in resected colon cancer: current status and future perspectives for integrating genomics into biomarker discovery. Oncologist 2010;15:390-404.

6. van 't Veer LJ, Dai H, van de Vijver MJ, He YD, Hart AA, Mao M, et al. Gene expression profiling predicts clinical outcome of breast cancer. Nature 2002;415:530-6.

7. Sanz-Pamplona R, Berenguer A, Cordero D, Riccadonna S, Sole X, Crous-Bou M, et al. Clinical value of prognosis gene expression signatures in colorectal cancer: a systematic review. PLoS One 2012;7:e48877.

8. Black ER, Falzon L, Aronson N. Gene Expression Profiling for Predicting Outcomes in Stage II Colon Cancer. Rockville (MD)2012.

9. van Malenstein H, Gevaert O, Libbrecht L, Daemen A, Allemeersch J, Nevens F, et al. A seven-gene set associated with chronic hypoxia of prognostic importance in hepatocellular carcinoma. Clin Cancer Res 2010;16:4278-88.

10. Semenza GL. Hypoxia-inducible factors: mediators of cancer progression and targets for cancer therapy. Trends Pharmacol Sci 2012;33:207-14.

11. Benjamini Y, Hochberg Y. Controlling the false discovery rate: a practical and powerful approach to multiple testing. Journal of the Royal Statistical Society: Series B 1995;57:289-300.

12. McShane LM, Altman DG, Sauerbrei W, Taube SE, Gion M, Clark GM, et al. REporting recommendations for tumour MARKer prognostic studies (REMARK). $\mathrm{Br} J$ Cancer 2005;93:387-91.

13. Jorissen RN, Gibbs P, Christie M, Prakash S, Lipton L, Desai J, et al. MetastasisAssociated Gene Expression Changes Predict Poor Outcomes in Patients with Dukes Stage B and C Colorectal Cancer. Clin Cancer Res 2009;15:7642-51.

14. Kaiser S, Park YK, Franklin JL, Halberg RB, Yu M, Jessen WJ, et al. Transcriptional recapitulation and subversion of embryonic colon development by mouse colon tumor models and human colon cancer. Genome Biol 2007;8:R131.

15. Smith JJ, Deane NG, Wu F, Merchant NB, Zhang B, Jiang A, et al. Experimentally derived metastasis gene expression profile predicts recurrence and death in patients with colon cancer. Gastroenterology 2010;138:958-68.

16. Goeman JJ, van de Geer SA, de Kort F, van Houwelingen HC. A global test for groups of genes: testing association with a clinical outcome. Bioinformatics 2004;20:93-9.

17. Geiss GK, Bumgarner RE, Birditt B, Dahl T, Dowidar N, Dunaway DL, et al. Direct multiplexed measurement of gene expression with color-coded probe pairs. Nat Biotechnol 2008;26:317-25. 
18. De Sousa EMF, Wang X, Jansen M, Fessler E, Trinh A, de Rooij LP, et al. Poorprognosis colon cancer is defined by a molecularly distinct subtype and develops from serrated precursor lesions. Nat Med 2013;19:614-8.

19. Liu Y, Bodmer WF. Analysis of P53 mutations and their expression in 56 colorectal cancer cell lines. Proc Natl Acad Sci U S A 2006;103:976-81.

20. Sarasqueta AF, Forte G, Corver WE, de Miranda NF, Ruano D, van Eijk R, et al. Integral analysis of p53 and its value as prognostic factor in sporadic colon cancer. BMC Cancer 2013;13:277.

21. Moon EJ, Brizel DM, Chi JT, Dewhirst MW. The potential role of intrinsic hypoxia markers as prognostic variables in cancer. Antioxid Redox Signal 2007;9:1237-94.

22. Yoshimura H, Dhar DK, Kohno H, Kubota H, Fujii T, Ueda S, et al. Prognostic impact of hypoxia-inducible factors 1alpha and 2alpha in colorectal cancer patients: correlation with tumor angiogenesis and cyclooxygenase-2 expression. Clin Cancer Res 2004;10:8554-60.

23. Sermeus A, Michiels C. Reciprocal influence of the p53 and the hypoxic pathways. Cell Death Dis 2011;2:e164.

24. Sadanandam A, Lyssiotis CA, Homicsko K, Collisson EA, Gibb WJ, Wullschleger S, et al. A colorectal cancer classification system that associates cellular phenotype and responses to therapy. Nat Med 2013;19:619-25.

25. Marisa L, de Reynies A, Duval A, Selves J, Gaub MP, Vescovo L, et al. Gene expression classification of colon cancer into molecular subtypes: characterization, validation, and prognostic value. PLoS Med 2013;10:e1001453.

26. Budinska E, Popovici V, Tejpar S, D'Ario G, Lapique N, Sikora KO, et al. Gene expression patterns unveil a new level of molecular heterogeneity in colorectal cancer. J Pathol 2013;231:63-76. 


\section{Legends to tables and figures}

Table 1: Clinical overview of published microarray data sets used for global performance testing of the hypoxia expression pattern and for development and optimization of the Colon Cancer Hypoxia Score.

Abbreviations: NA, not available - MSS, microsatellite stable - MSI, microsatellite instable

Table 2: Overview of the 21 gene signature with their relative direction in vitro under hypoxia and cellular processes involved. TP53 was added to the signature and eventually incorporated in the CCHS.

Abbreviations: CCHS, colon cancer hypoxia score

Table 3: Clinical and pathological features of the Leuven cohort as well as the AMC-AJCCII-90 data set (16). Abbreviations: NA, not available - Median FU, median follow-up defined as time to relapse or last contact.

Table 4: Univariate and multivariate Cox regression analysis on all clinical and pathological variables in the Leuven cohort. The Colon Cancer Hypoxia Score (CCHS) is an independent predictor of disease recurrence.

Abbreviations: $\mathrm{Cl}$, Confidence Interval

Figure 1: Process to obtain the Colon Cancer Hypoxia Score. Overlap between three published data sets and the hypoxia gene expression pattern in CaCo-2 cells was used to downsize the 
number of genes to 21 . After adding TP53, a backward regression analysis was performed to obtain a six gene score.

Figure 2: Inclusion and selection process of the stage II/III colon cancer patients in our center. Of the 162 colon cancer patients included in this study, after clinical and technical selection, the expression levels of 126 patients was successfully determined.

Figure 3a: Kaplan-Meier curve for disease free survival in the Leuven cohort $(n=126)$.

Figure 3b: AJCC disease stage and Colon Cancer Hypoxia Score (CCHS) devide patients in three groups with significant differences in disease free survival. When the patients of AJCC Patients with stage II disease and a high CCHS have comparable outcome to patients with stage III disease and a low CCHS.

Figure 3c: Kaplan-Meier curve for disease free survival in the Amsterdam cohort $(n=90)$. 
Table 1

\begin{tabular}{|c|c|c|c|c|}
\hline Author & Jorissen & Aronow & \multicolumn{2}{|c|}{ Smith } \\
\hline Reference & 13 & 14 & \multicolumn{2}{|c|}{15} \\
\hline & & & VMC database & MCC database \\
\hline Data set ID & GSE13294 & GSE5206 & GSE17537 & GSE17536 \\
\hline Used for & Training signature & Training signature & Training signature & Developing score \\
\hline Array type & \multicolumn{4}{|c|}{ Affymetrix Human Genome U133 Plus 2.0 Array } \\
\hline Sample type & Fresh frozen & Fresh frozen & Fresh frozen & Fresh frozen \\
\hline N samples & 74 & 105 & 55 & 177 \\
\hline N Colon cancer & 74 & 100 & 55 & 177 \\
\hline Rectal cancer included & Yes & Yes & Yes & Yes \\
\hline $\mathrm{N}$ other & & 5 normal mucosa & & \\
\hline Age (median) (yrs) & NA & 66 & 62 & 66 \\
\hline Min & & 26 & 23 & 26 \\
\hline $\operatorname{Max}$ & & 92 & 94 & 92 \\
\hline $\operatorname{Sex}(M / F)$ & NA & & & \\
\hline Male & & $46(46 \%)$ & $26(47 \%)$ & $96(54 \%)$ \\
\hline Female & & 54 (54\%) & $29(53 \%)$ & $81(46 \%)$ \\
\hline AJCC stage & NA & & & \\
\hline 1 & & $15(15 \%)$ & $4(7 \%)$ & $24(14 \%)$ \\
\hline II & & $29(29 \%)$ & $15(27 \%)$ & $57(32 \%)$ \\
\hline III & & $33(33 \%)$ & $19(35 \%)$ & $57(32 \%)$ \\
\hline IV & & $20(20 \%)$ & $17(31 \%)$ & $39(22 \%)$ \\
\hline NA & & $3(3 \%)$ & 0 & 0 \\
\hline Differentiation & NA & & & \\
\hline Good & & $8(8 \%)$ & $1(2 \%)$ & $16(9 \%)$ \\
\hline Moderate & & $78(78 \%)$ & $32(58 \%)$ & $134(76 \%)$ \\
\hline Poor & & $10(10 \%)$ & $3(5 \%)$ & $27(15 \%)$ \\
\hline NA & & $4(4 \%)$ & $19(35 \%)$ & 0 \\
\hline Recurrence & NA & & & \\
\hline Yes & & $23(23 \%)$ & $19(34 \%)$ & $36(24 \%)$ \\
\hline No & & $77(77 \%)$ & $36(66 \%)$ & $109(62 \%)$ \\
\hline NA & & & & $32(18 \%)$ \\
\hline Median FU (months) & NA & NA & 50.2 & 42.3 \\
\hline
\end{tabular}




\begin{tabular}{|l|l|l|l|l|}
\hline Min & & & 0.4 & 0.9 \\
\hline Max & & & 111 & 142.5 \\
\hline Microsatellite instability & & NA & NA & NA \\
\hline MSS & $63(85 \%)$ & & & \\
\hline MSI & $11(15 \%)$ & & & \\
\hline
\end{tabular}


Table 2

\begin{tabular}{|c|c|c|c|}
\hline Official gene symbol & Direction In vitro & Gene name & Processes involved \\
\hline BCCIP & $\nabla$ & BRCA2 and CDKN1A-interacting protein isoform C & DNA metabolic / repair \\
\hline BNIP3L & $\boldsymbol{\Delta}$ & BCL2/adenovirus E1B 19 kDa protein-interacting protein 3-like & apoptosis \\
\hline BTBD14A & $\boldsymbol{\Delta}$ & nucleus accumbens-associated protein 2 & unknown \\
\hline DDIT4 & $\mathbf{\Delta}$ & DNA damage-inducible transcript 4 protein & apoptosis / hypoxia \\
\hline ERRFI1 & $\boldsymbol{\Delta}$ & ERBB receptor feedback inhibitor 1 & GTPase regulation \\
\hline FAM46C & $\boldsymbol{\nabla}$ & hypothetical protein LOC54855 & unknown \\
\hline GADD45B & $\Delta$ & growth arrest and DNA damage-inducible protein GADD45 beta & apoptosis \\
\hline HBP1 & $\Delta$ & HMG box-containing protein 1 & cell cycle \\
\hline ING5 & $\boldsymbol{\nabla}$ & inhibitor of growth protein 5 & DNA metabolic / repair \\
\hline INSIG2 & $\Delta$ & insulin-induced gene 2 protein & ER-nuclear signaling \\
\hline KLF7 & $\Delta$ & Krueppel-like factor 7 & cell morphogenisis \\
\hline MPHOSPH6 & $\boldsymbol{\nabla}$ & M-phase phosphoprotein 6 & cell cycle \\
\hline NNMT & $\Delta$ & nicotinamide $\mathrm{N}$-methyltransferase & $\mathrm{N}$-methyltransferase \\
\hline P4HA1 & $\Delta$ & prolyl 4-hydroxylase subunit alpha-1 isoform 1 precursor & metabolic processes \\
\hline P4HA2 & $\boldsymbol{\Delta}$ & prolyl 4-hydroxylase subunit alpha-2 isoform 1 precursor & metabolic processes \\
\hline PLAUR & $\Delta$ & urokinase plasminogen activator surface receptor isoform 3 precursor & metabolic processes \\
\hline $\mathrm{RHOU}$ & $\Delta$ & rho-related GTP-binding protein RhoU & cell cycle \\
\hline TMCC1 & $\boldsymbol{\Delta}$ & transmembrane and coiled-coil domains protein 1 isoform a & transmembrane signaling \\
\hline UBE2H & $\Delta$ & ubiquitin-conjugating enzyme E2 $\mathrm{H}$ isoform 1 & proteolysis \\
\hline ULBP2 & $\Delta$ & NKG2D ligand 2 precursor & transmembrane signaling \\
\hline XIAP/BIRC4 & $\Delta$ & baculoviral IAP repeat-containing protein 4 & apoptosis \\
\hline TP53 & NA & tumor protein $\mathrm{p} 53$ & apoptosis/cell cycle \\
\hline
\end{tabular}




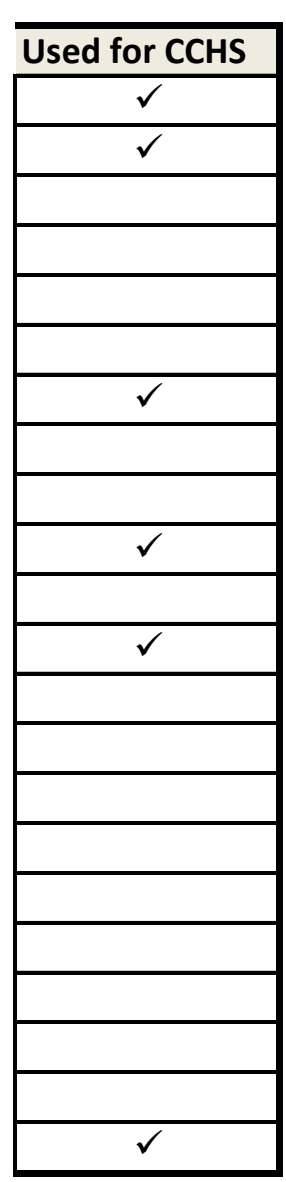


Table 3

\begin{tabular}{|c|c|c|c|c|}
\hline & \multicolumn{3}{|c|}{ Leuven Cohort } & \multirow[t]{2}{*}{ AMC-AJCC-II } \\
\hline & All patients & Stage II & Stage III & \\
\hline Patient number & 126 & 71 & 55 & 90 \\
\hline Age (median) (yrs) & 71.2 & 70 & 72.9 & 73.4 \\
\hline Min (yrs) & 35.9 & 35.9 & 38.8 & 34.6 \\
\hline Max (yrs) & 92.9 & 92.9 & 86.2 & 95.1 \\
\hline \multicolumn{5}{|l|}{ Sex } \\
\hline Male & $67(53 \%)$ & $34(48 \%)$ & $33(60 \%)$ & $42(47 \%)$ \\
\hline Female & $59(47 \%)$ & $37(52 \%)$ & $22(40 \%)$ & $48(53 \%)$ \\
\hline \multicolumn{5}{|l|}{ Localisation } \\
\hline Right sided tumor & $63(50 \%)$ & $39(55 \%)$ & $24(43,5 \%)$ & $48(53 \%)$ \\
\hline Left sided tumor & $63(50 \%)$ & $32(45 \%)$ & $31(56,5 \%)$ & $42(47 \%)$ \\
\hline T-stage & & & & NA \\
\hline $\mathrm{T} 2$ & $4(3 \%)$ & $0(0 \%)$ & $4(7 \%)$ & \\
\hline T3 & $109(86,5 \%)$ & $67(94 \%)$ & $42(76,5 \%)$ & \\
\hline $\mathrm{T} 4$ & $13(10,5 \%)$ & $4(6 \%)$ & $9(16,4 \%)$ & \\
\hline N-stage & & & & NA \\
\hline NO & $71(56 \%)$ & $71(100 \%)$ & $0(0 \%)$ & \\
\hline N1 & 39 (31\%) & $0(0 \%)$ & 39 (71\%) & \\
\hline $\mathrm{N} 2$ & $16(13 \%)$ & $0(0 \%)$ & $16(29 \%)$ & \\
\hline \multicolumn{5}{|l|}{ AJCC stage } \\
\hline II & $71(56 \%)$ & $71(100 \%)$ & $0(0 \%)$ & $90(100 \%)$ \\
\hline III & $55(44 \%)$ & $0(0 \%)$ & $55(100 \%)$ & $0(0 \%)$ \\
\hline Mucinous type & & & & NA \\
\hline Yes & 36 (29\%) & $22(31 \%)$ & $41(74,5 \%)$ & \\
\hline No & $90(71 \%)$ & 49 (69\%) & $14(25,5 \%)$ & \\
\hline Differentiation & & & & NA \\
\hline Good & $14(11 \%)$ & $7(10 \%)$ & $7(13 \%)$ & \\
\hline Moderate & $63(50 \%)$ & $40(56,5 \%)$ & $23(42 \%)$ & \\
\hline Poor & 45 (36\%) & $20(28 \%)$ & $25(45 \%)$ & \\
\hline Undifferentiated & $1(1 \%)$ & $1(1,5 \%)$ & $0(0 \%)$ & \\
\hline Not available & $3(2 \%)$ & $3(4 \%)$ & $0(0 \%)$ & \\
\hline
\end{tabular}




\begin{tabular}{|l|l|l|l|l|}
\hline Peritoneal invasion & & & & NA \\
\hline Yes & $1(1 \%)$ & $1(1 \%)$ & $0(0 \%)$ & \\
\hline No & $125(99 \%)$ & $70(99 \%)$ & $55(100 \%)$ & \\
\hline Extramural venous invasion & & & & NA \\
\hline Yes & $36(28,6 \%)$ & $11(15 \%)$ & $25(45 \%)$ & \\
\hline No & $81(64,3 \%)$ & $59(84 \%)$ & $22(40 \%)$ & \\
\hline NA & $9(7,1 \%)$ & $1(1 \%)$ & $8(15 \%)$ & \\
\hline Resection margin & & & & NA \\
\hline Positive & $1(1 \%)$ & $0(0 \%)$ & $1(2 \%)$ & \\
\hline Negative & $124(98 \%)$ & $71(100 \%)$ & $53(96 \%)$ & \\
\hline NA & $1(1 \%)$ & $0(0 \%)$ & $1(2 \%)$ & \\
\hline Bowel perforation & & & & NA \\
\hline Yes & $5(4 \%)$ & $3(4 \%)$ & $2(4 \%)$ & \\
\hline No & $121(96 \%)$ & $68(96 \%)$ & $53(96 \%)$ & \\
\hline Examined lymph nodes & & & & NA \\
\hline 12 or more & $83(66 \%)$ & $49(69 \%)$ & $34(62 \%)$ & \\
\hline Less than 12 & $42(33 \%)$ & $22(31 \%)$ & $20(36 \%)$ & \\
\hline NA & $1(1 \%)$ & $0(0 \%)$ & $1(2 \%)$ & \\
\hline Adjuvant chemotherapy & & & & NA \\
\hline Yes & $63(50 \%)$ & $50(70,4 \%)$ & $42(76,5 \%)$ & \\
\hline No & $63(50 \%)$ & $21(29,6 \%)$ & $13(23,5 \%)$ & \\
\hline Relapse & & & & \\
\hline Yes & $35(28 \%)$ & $12(17 \%)$ & $23(42 \%)$ & $19(21 \%)$ \\
\hline No & $91(72 \%)$ & $59(83 \%)$ & $32(58 \%)$ & $71(79 \%)$ \\
\hline Median FU (months) & 45.42 & 49.14 & 23.1 & 39.3 \\
\hline Min (months) & 1.3 & 1.3 & 1.5 & 1.6 \\
\hline Max (months) & 76.4 & 76.4 & 73.9 & 120 \\
\hline
\end{tabular}


Table 4

\begin{tabular}{|c|c|c|c|c|c|c|c|c|c|}
\hline & \multicolumn{5}{|c|}{ Univariate Cox regression analysis } & \multicolumn{4}{|c|}{ Multivariate Cox regression analys } \\
\hline & \multirow{2}{*}{$\begin{array}{c}\text { Beta } \\
\text { coefficient }\end{array}$} & \multirow{2}{*}{$p$-value } & \multirow{2}{*}{$\begin{array}{c}\text { Hazard } \\
\text { Ratio }\end{array}$} & \multicolumn{2}{|c|}{$95,0 \% \mathrm{Cl}$} & \multirow{2}{*}{$\begin{array}{c}\text { Beta } \\
\text { coefficient }\end{array}$} & \multirow[b]{2}{*}{ p-value } & \multirow{2}{*}{$\begin{array}{c}\text { Hazard } \\
\text { Ratio }\end{array}$} & \multirow{2}{*}{$\begin{array}{r}95,0 \\
\text { Lower }\end{array}$} \\
\hline & & & & Lower & Upper & & & & \\
\hline Age & 0.03 & 0.070 & 1.03 & 1.00 & 1.07 & & & & \\
\hline Location (left vs right) & 0.13 & 0.701 & 1.14 & 0.59 & 2.21 & & & & \\
\hline Stage (III vs II) & 1.23 & 0.001 & 3.41 & 1.69 & 6.86 & 0.95 & 0.017 & 2.58 & 1.19 \\
\hline Peritoneal invasion (yes vs no) & 1.30 & 0.203 & 3.66 & 0.50 & 26.89 & & & & \\
\hline Extramural venous invasion (yes vs no) & 1.60 & $<0,001$ & 4.95 & 2.43 & 10.07 & 1.17 & 0.003 & 3.21 & 1.50 \\
\hline Resection margin (positive vs negative) & 1.47 & 0.149 & 4.36 & 0.59 & 32.24 & & & & \\
\hline Bowel perforation (yes vs no) & 0.70 & 0.336 & 2.02 & 0.48 & 8.45 & & & & \\
\hline Mucinous type (yes vs no) & -0.27 & 0.506 & 0.76 & 0.35 & 1.68 & & & & \\
\hline Differentiation & & 0.856 & & & & & & & \\
\hline Differentiation (moderate vs good) & 0.38 & 0.541 & 1.46 & 0.43 & 4.97 & & & & \\
\hline Differentiation (poor vs good) & 0.66 & 0.296 & 1.94 & 0.56 & 6.77 & & & & \\
\hline Adjuvant chemotherapy (yes vs no) & 0.19 & 0.587 & 1.20 & 0.62 & 2.35 & & & & \\
\hline Colon Cancer Hypoxia Score (high vs low) & 0.91 & 0.008 & 2.49 & 1.27 & 4.86 & 0.95 & 0.013 & 2.58 & 1.23 \\
\hline Lymph nodes examined (12 or more vs less than 12 ) & -0.73 & 0.034 & 0.48 & 0.25 & 0.95 & -0.40 & 0.283 & 0.67 & 0.33 \\
\hline
\end{tabular}




$$
\begin{aligned}
& \text { is } \\
& \text { \% Cl } \\
& \hline \text { Upper } \\
& \hline \\
& \hline \\
& \hline 5.61 \\
& \hline 6.89 \\
& \hline \\
& \hline \\
& \hline \\
& \hline \\
& \hline \\
& \hline 5.43 \\
& \hline 1.39 \\
& \hline
\end{aligned}
$$




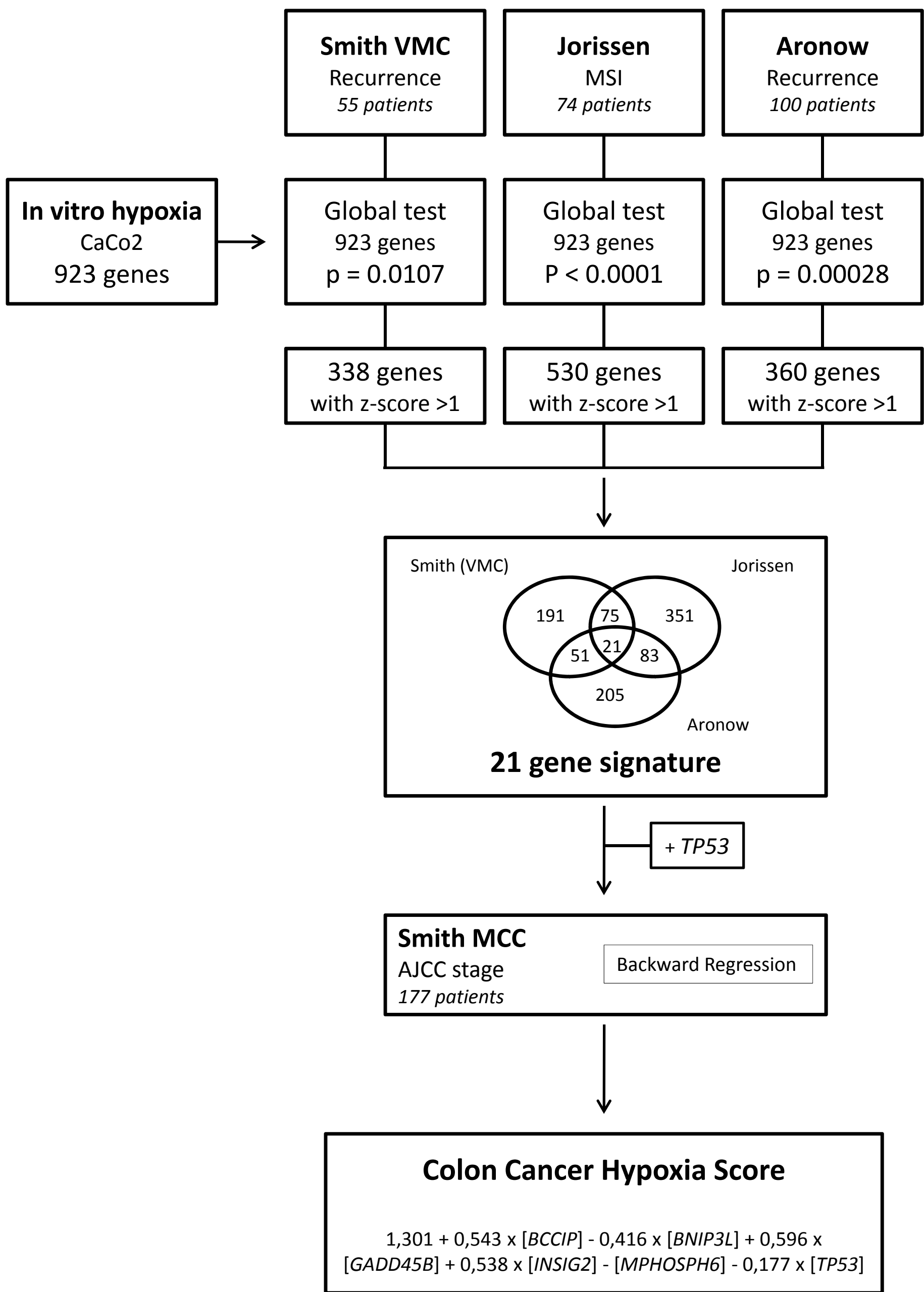

Figure 1 


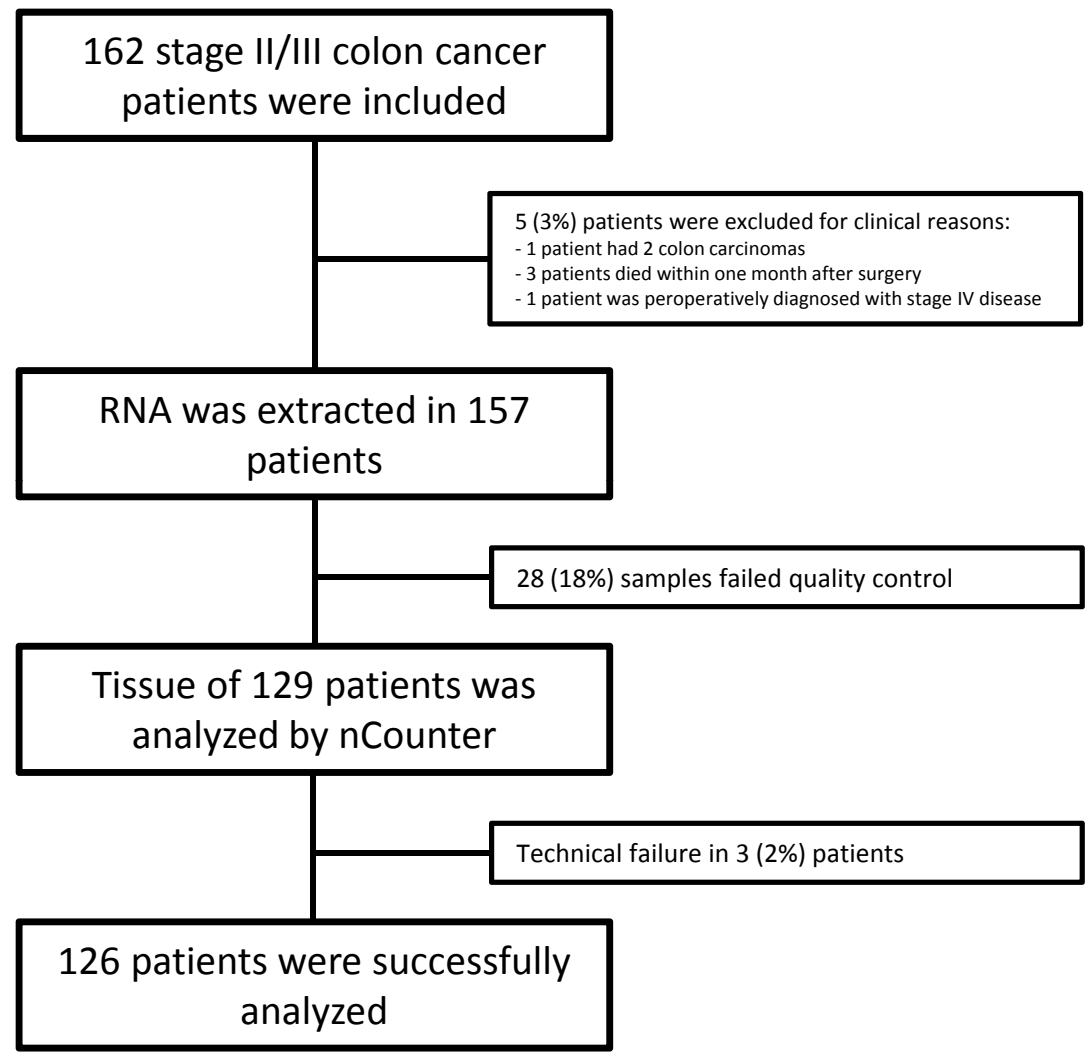

Figure 2 


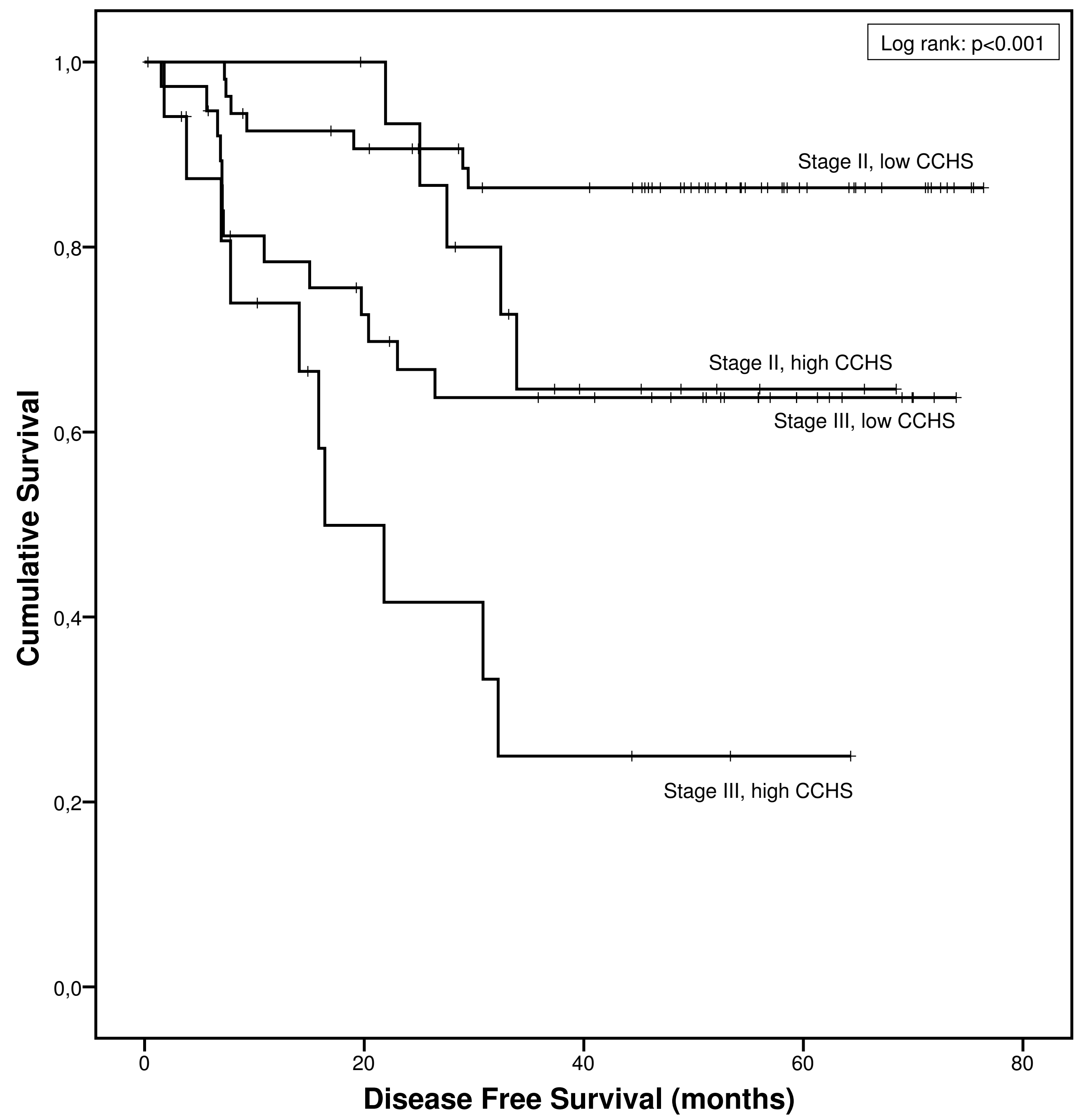

Figure $3 b$ 


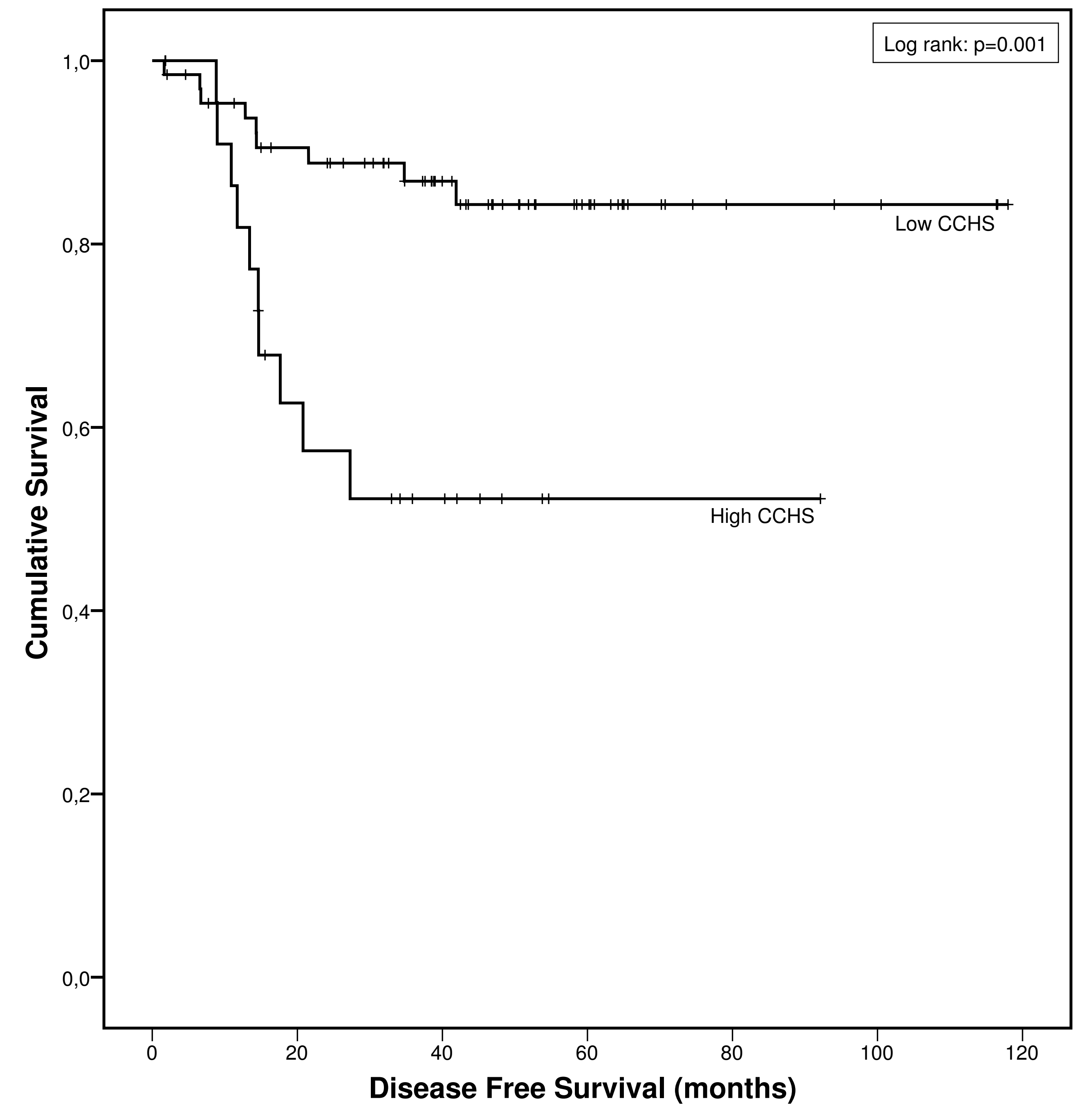

Figure 3c 